\title{
Are hospitality venue employees aware and do they support the State-wide Regulation of Smoking Law in Lagos state Nigeria?
}

\author{
Oluwakemi Ololade Odukoya ${ }^{1}$, Uche Ohanusi $^{1}$, Banji Olokodana $^{1}$
}

\begin{abstract}
INTRODUCTION A law controlling tobacco smoking in public places in Lagos state, Nigeria was enacted in February 2014. This study examines the awareness and support of workers in restaurants, bars and nightclubs for the provisions of the law.

METHODS This cross-sectional study was conducted in July 2014 shortly after the law was enacted. Three hundred and forty hospitality venues (restaurants, bars and nightclubs) were randomly selected one eligible worker was interviewed using a pre tested questionnaire.

RESULTS Only 57.6\% were aware of the existence of the law. Awareness of the specific places where the smoking is prohibited and the specific tennets of the law were very low. More than half of the respondents supported the prohibition of tobacco smoking in most public places. Many $(47.1 \%)$ of the respondents felt that the law would decrease revenue, however majority (72.9\%) felt that the law would reduce smoking rates. Support for smoking bans was associated with the presence of workplace smoking restrictions and a lack of tobacco sales on the premises. conclusions Awareness of the State Regulation of smoking law was low however ,many of the workers support many aspects of the law. They however, believed the law would negatively impact revenue. Mechanisms to educate these workers and deal with their misconceptions of the perceived negative effects of the law should be implemented. Monitoring the awareness and support of these workers for smoke-free legislation is essential, in line with the guidelines for Article 8 of the WHO FCTC.
\end{abstract}

\author{
AFFILIATION \\ 1 Department of Community \\ Medicine, Lagos University \\ Teaching Hospital, Idi-Araba, \\ Lagos state, Nigeria \\ CORRESPONDENCE TO \\ Oluwakemi Ololade Odukoya \\ College of Medicine, University \\ of Lagos, Ishaga road, 12003 \\ Idi-araba, Nigeria

\section{KEY WORDS} \\ workers, support, awareness, \\ smoke-free laws, hospitality \\ venues
}

\section{INTRODUCTION}

There is abounding evidence that exposure to second-hand smoke (SHS) causes many serious diseases ${ }^{1-3}$. Among nonsmoking adults, second-hand smoke (SHS) is associated with an increased risk of coronary heart disease and many cancers, primarily of the lung, larynx and pharynx ${ }^{1,3}$. Globally, more than a third of all people are regularly exposed to the harmful effects of tobacco smoke ${ }^{2}$. This exposure is responsible for an estimated 600,000 deaths per year, and about $1 \%$ of the global burden of disease worldwide ${ }^{2}$. This risk factor is prevalent in practically every region of the world. Even in a country like Nigeria, where smoking rates are comparatively lower than in most low and middle income countries (LMIC), 2.7 million and 6.4 million adults were reported to be exposed to SHS in the workplace and when visiting restaurants in the past month respectively ${ }^{4}$. There is no safe level of exposure to SHS. Enacting and implementing 100\% smoke-free policies is therefore the most effective way to reduce exposure to tobacco smoke among non-smokers ${ }^{1,5}$.

In the light of the overwhelming evidence of the negative health effects of SHS, article 8 of the World Health Organisation Framework Convention on Tobacco Control (WHO FCTG) requires countries to adopt and implement measures to protect all people from tobacco smoke ${ }^{6}$. Many countries have therefore approved legislation for smoke-free public places. In Africa, countries like Mauritius, South Africa and Kenya have successfully passed national smoke free laws ${ }^{7}$. Nigeria signed the WHO FCTC in 2004 and ratified it in 2005 and since then efforts have been on going to domesticate the provisions of the FCTC. However many non-smoking Nigerians are exposed to $\mathrm{SHS}^{4,8}$

Lagos state, the commercial capital of Nigeria, is one of the most populous cities in the world and the most populous in Africa. To protect her people from the harmful effects of SHS, 
the Lagos state government passed a State "Regulation of smoking law" in February 2014, ${ }^{9,10}$. This law prohibits smoking in a variety of public places including restaurants, however partial restrictions were made for bars and nightclubs. Under this law, owners of bars and nightclubs have the option of providing designated "smoking areas" within their premises. It is stated that these smoking areas are required to have good ventilations and may be equipped with ventilating equipment, however this is not mandatory. The law was scheduled to take effect six months after it was signed. However, it remains to be seen exactly if and how this law will be successfully implemented in Lagos state.

In response to the passage of the law, we set out to assess the awareness and support for the newly enacted law shortly after it was enacted but before its full implementation. We were particularly interested in assessing the employees support and factors associated with their support for comprehensive smoke free bans in restaurants as opposed to venues like bars and nightclubs, which are not currently covered by this law.

\section{METHODS}

\section{Setting and Somple size}

This cross-sectional descriptive study was conducted among employees in restaurants, bars and nightclubs registered with the Lagos State Ministry of Tourism. Only establishments registered under the Lagos State Ministry of Tourism and InterGovernmental relations and operated as either restaurants, bars or nightclubs were used in this study, regardless of their organisational smoking policies. A list of the 969 registered hospitality venues was obtained from this Ministry. Three hundred and forty eligible establishments were randomly selected from this list using a table of random numbers until the minimum sample size was reached.

Eligible respondents must have worked in any of these establishments for at least six months and their work must involve personal contact with clients for them to have been included in the study; hence drivers, despatch riders and other ad-hoc staff were excluded. The minimum sample size was estimated to be 289 using prevalence of awareness of statelevel smoke free policy of $75 \%$ from a similar study in Osun state, Nigeria 11 a $95 \%$ level of confidence and a $5 \%$ margin of error. This was increased to 340 to make allowance for nonresponses.

\section{Data Collection}

Data was collected using a structured questionnaire designed by the authors based on a review of the literature and the contents of the recently passed "State regulation of smoking law". The questionnaire was designed to elicit information on the respondents' socio-demographic characteristics, workplace characteristics, awareness and knowledge of the Lagos State anti-smoking law, attitudes towards specific components of the law and its violations. The questionnaire was assessed by two of the authors for face and content validity and thereafter pre-tested among a group of twenty persons similar to study participants but not in establishments that were selected as part of the study. Appropriate corrections were made thereafter. Test-re-test reliability showed a cronbach alpha of 0.70 .

Data was collected from the respondents by trained interviewers. Recruited interviewers were required to be fluent in both English Language and Pidgin English (which is widely spoken across ethnic groups in Lagos state). Interviewers were also required to have at least a secondary school education. After recruitment, interviewers received a one-day training on questionnaire administration in both languages.

Once the interviewer arrived at the venue, he/she was required to seek and informed consent from the owner (or any person with similar authorities) before commencement of the survey. If consent was declined, the interviewer would simply move on to the next randomly selected venue. However, only seven venues declined consent and these venues were promptly replaced. After receiving informed consent from the venue owner, he/she obtained a list of all the eligible respondents in each venue and one respondent was selected randomly by simple balloting. Only one eligible and consenting worker was randomly selected in each establishment and interviewed to avoid a clustering effect. If that person declined to participate, he/she was replaced by another randomly selected eligible person. Data was collected in a private secure place within the premises to ensure confidentiality.

\section{Ethics}

Approval for this study was obtained from the Ethics and Research Committee of the Lagos University Teaching Hospital. Permission was also obtained from the Lagos state Ministry of Tourism and Intergovernmental relations and from the owners of each establishment. Written informed consent was obtained from each worker. No names were printed on the questionnaires and the employees were assured of the confidential nature of the study. They were also given the choice to participate or not in the study and were aware that they could withdraw from the study whenever they felt like doing so.

\section{Statistic Approach}

Data was analysed using SPSS 17.0 statistical software. 
We conducted a bivariate analysis with two outcome variables; respondents' support for a complete ban on smoking in restaurants; and their support for a ban on smoking in nightclubs and bars. We separated the support for a complete ban on smoking in restaurants, bars and nightclubs because the "State regulation of smoking law" completely bans smoking in restaurants but only offers partial restrictions in bars and nightclubs which impedes its compliance with $100 \%$ smoke free environments as recommended by the WHO FCTC. Questions assessing support for complete smoke-free bans in specific public places were initially asked on a three-point Likert scale; (agree, neutral, disagree) however, to achieve dichotomous outcome variables we created two new variables based on their responses. Those who answered in the affirmative (agree) were considered to be in support of such a ban while all other responses (neutral and disagree) were considered not to be in support of the ban. $p$ values of $<0.05$ were considered to be statistically significant. Thereafter, we conducted a multivariate analysis for each outcome variable using the variables that were statistically significant using a block entry approach on SPSS, after checking for multi-colinearity and homoscedascity of the variables. Results were presented in odds ratios and $95 \%$ confidence intervals.

\section{RESULTS}

Socio-demographic and workplace characteristics of the respondents

The socio-demographic and workplace characteristics of the respondents are depicted in Table 1. More than half (57.7\%) of the respondents worked in establishments where bar services were rendered, $46.2 \%$ worked in places that offered restaurant services while only $8.8 \%$ worked in venues that had facilities for nightclubs. Many of their workplaces $(61.2 \%)$ were indoor only establishments, while $15.9 \%$ offered their services only outdoors. Twenty-two per cent of the respondents' workplaces had both indoor and outdoor facilities. Tobacco products were sold in $37.6 \%$ of the respondents' workplaces. In about a third of the workplaces, smoking was not allowed anywhere on the premises. $22.6 \%$ had designated indoor smoking areas while $17.1 \%$ allowed smoking outdoors only. In $26.8 \%$ of the workplaces, there were no smoking restrictions at all.

\section{Awareness and perceived effects of the law and support for} smoke-free places

As depicted in table 2 , only $57.6 \%$ of the respondents were aware of the "State regulation of smoking law". Their most common sources of information were the mass media (65.3\%), and by word-of-mouth from friends/acquaintances (29.4\%).
Table 1: Socio demographic characteristics of the workers in restaurants, bars and nightclubs in Lagos State, Nigeria.

\begin{tabular}{|c|c|}
\hline Variables (n-310) & Frequency $(\%)$ \\
\hline \multicolumn{2}{|c|}{ Age (years) } \\
\hline$<21$ & $59(17.4)$ \\
\hline $21-30$ & $195(57.4)$ \\
\hline $31-40$ & $53(15.6)$ \\
\hline$>40$ & $27(7.9)$ \\
\hline Mean+ S.D & $27.7+8.6$ \\
\hline \multicolumn{2}{|c|}{ Gender } \\
\hline Male & $191(56.2)$ \\
\hline Female & $149(43.8)$ \\
\hline \multicolumn{2}{|c|}{ Highest level of education attained } \\
\hline Primary Education & $5(1.5)$ \\
\hline Secondary Education & $153(45.0)$ \\
\hline Tertiary education & $182(53.5)$ \\
\hline \multicolumn{2}{|c|}{ Ethnicity } \\
\hline Yoruba & $175(47.7)$ \\
\hline Ibo & $106(40.9)$ \\
\hline Hausa/Others & $59(17.4)$ \\
\hline \multicolumn{2}{|c|}{ Religion } \\
\hline Christianity & $276(77.9)$ \\
\hline Islam & $59(22.1)$ \\
\hline Other & $5(1.5)$ \\
\hline
\end{tabular}

Marital status

$\begin{array}{lc}\begin{array}{ll}\text { Single } \\ \text { Married }\end{array} & 258(75.8) \\ \text { Divorced/Separated/Widowed } & 76(22.4) \\ & 6(1.8) \\ \text { Waiter/Waitress } & \text { Type of work } \\ \text { Manager } & 954(68.8) \\ \text { Other } & 11(3.2)\end{array}$

Smoking status

$\begin{array}{ll}\text { Current smoker } & 23(6.8) \\ \text { Ex-smoker } & 45(13.2) \\ \text { Never-smoker } & 272(80.0) \\ \text { Total } & 340(100.0)\end{array}$

!Other ethnicities included Delta, Edo, Urhobo, Kwara, Efik, Igala, Benue and Cross-river

Only $7.9 \%$ were aware of the exact date the law would come into effect. Awareness of the specific places where the smoking is prohibited and the specific aspects of the law were also very low. More than half of the respondents support the prohibition of tobacco smoking in most public places. Support was highest for hospitals (88.2\%); schools (86.8\%); public transportation (84.8\%); Shops/Markets (79.7\%); Cinemas 
Table 2: Awareness of the STATE REGU LATION OF SMOKING LAW among workers in restaurants, bars and nightclubs in Lagos State, Nigeria Lagos smoking law.

\begin{tabular}{|c|c|}
\hline $\begin{array}{l}\text { Respondent is aware of the Lagos state } \\
\text { regulation of smoking law. }\end{array}$ & Frequency $(\%)$ \\
\hline \multicolumn{2}{|l|}{ Sources of information* } \\
\hline Television & $75(37.1)$ \\
\hline Radio & $57(28.2)$ \\
\hline Newspapers & $33(16.3)$ \\
\hline Friends/Acquaintances & $59(29.2)$ \\
\hline Health workers & $27(13.4)$ \\
\hline Internet & $19(9.4)$ \\
\hline $\begin{array}{l}\text { Respondent is aware of the date when the law } \\
\text { will take effect }(n=202)\end{array}$ & $16(7.9)$ \\
\hline \multicolumn{2}{|c|}{$\begin{array}{l}\text { Respondent is aware that the law prohibits tobacco smoking in the } \\
\text { following places }{ }^{*}(n=202)\end{array}$} \\
\hline Hospitals & $106(52.5)$ \\
\hline Buses/Taxis & $86(42.6)$ \\
\hline Bars and Nightclubs & $49(24.3)$ \\
\hline Schools & $91(45.0)$ \\
\hline Restaurants & $70(34.7)$ \\
\hline In front of a child & $103(29.6)$ \\
\hline $\begin{array}{l}\text { Aware that the law makes provisions for } \\
\text { smoking/non-smoking sections in indoor areas of } \\
\text { some hospitality venues }(n=202)\end{array}$ & $57(51.0)$ \\
\hline $\begin{array}{l}\text { Aware that the law makes it compulsory for } \\
\text { hospitality venues to hang smoke-free signs in/ } \\
\text { outside their venues }(n=202)\end{array}$ & $126(62.4)$ \\
\hline
\end{tabular}

(79.1\%) and restaurants (76.8\%). Less than half supported a ban on smoking in hotels (49.1\%), bars and nightclubs $(37.9 \%)$. The majority $(77.3 \%)$ supported the compulsory hanging of smoke-free signs in front of hospitality venues.

Many of the respondents felt that the law would either decrease $(47.1 \%)$ or have no effect $(38.8 \%)$ on revenue. Similarly, more than half $(52.4 \%)$ of the respondents felt that the law would reduce or have no effect on (27.4\%) client satisfaction, however the majority $(72.9 \%)$ felt that the law would reduce smoking rates. Most of the respondents (76.5\%) agreed that when the law is violated, only the smoker should be penalized, while $35.3 \%$ believe that both should be penalised. Regarding smoker penalties for violations of the law, 70.3\% supported a monetary fine over a prison term for the smoker (27.7\%) while only $32.3 \%$ agree that the venue owner should also be fined. Very few (8.8\%) support a prison term for the owner for violations and $7.3 \%$ supported the notion to close the venue if the law is violated.

Factors associated with support for smoke-free bans in restaurants, bars and nightclubs

Support for smoking bans in restaurants was associated with the presence of workplace smoking restrictions and a lack of tobacco sales in the respondents' workplace while support for bans in bars and nightclubs was associated with workplace smoking restrictions and the respondents' ethnicity as depicted in table 4. After controlling for age, gender, level of education, and smoking status, a regression analysis showed that respondents who worked in venues where tobacco was sold were less likely (OR, 0.6; 95\% CI: 0.37-0.96) to support a ban on smoking in bars/nightclubs. Compared with those of the Yoruba ethnicity, Non-Yorubas were more supportive of

Table 3: Support for a ban on tobacco smoking in specific public places among workers in restaurants, bars and nightclubs in Lagos State, Nigeria

\begin{tabular}{llll}
$\begin{array}{l}\text { Respondent supports a ban on tobacco smoking in the following places } \\
\text { (n } 310)\end{array}$ & Yes Freq $(\%)$ & Undecided Freq( $(\%)$ & Vo Freq. $(\%)$ \\
\hline Restaurants & $261(76.8)$ & $33(9.7)$ & $46(13.5)$ \\
Bars and nightclubs & $129(37.9)$ & $54(15.9)$ & $157(46.2)$ \\
Hospitals & $300(88.2)$ & $26(7.6)$ & $14(4.1)$ \\
Schools & $295(86.8)$ & $24(7.1)$ & $19(5.6)$ \\
Buses/Taxis & $287(84.4)$ & $35(10.3)$ & $18(5.3)$ \\
Airports & $259(76.2)$ & $39(11.5)$ & $42(12.4)$ \\
Hotels & $167(49.1)$ & $46(13.5)$ & $127(37.4)$ \\
Cinemas & $269(79.1)$ & $37(10.9)$ & $34(10.0)$ \\
Public toilets & $226(66.5)$ & $46(13.5)$ & $68(20.0)$ \\
Shops/Markets & $271(79.7)$ & $37(10.9)$ & $32(9.4)$ \\
Lifts & $276(81.2)$ & $46(13.5)$ & $21(6.2)$
\end{tabular}




\section{Research Paper}

Table 4: A bivariate analysis showing the factors associated with respondents support for smoking bans in restaurants, bars and nightclubs among the workers in hospitality venues in Lagos State, Nigeria.

\begin{tabular}{|c|c|c|c|c|c|c|c|}
\hline \multirow[t]{2}{*}{ Variables } & \multicolumn{3}{|c|}{ Ban on smoking in restaurants } & \multicolumn{4}{|c|}{ Ban on smoking in bars and nightclubs } \\
\hline & $\begin{array}{l}\text { In support } \\
(n=261) \%\end{array}$ & $\begin{array}{l}\text { Not in support } \\
(n=79) \%\end{array}$ & P-value & In support $(n=129) \%$ & $\begin{array}{l}\text { Not in support } \\
(n=211) \%\end{array}$ & P-value & Total\% \\
\hline Mean age (SD) & $27.6(8.3)$ & $28.1(9.1)$ & 0.674 & $27.8(8.7)$ & $27.7(8.4)$ & 0.865 & $27.7(8.6)$ \\
\hline \multicolumn{8}{|c|}{ Sex } \\
\hline Male & 74.3 & 25.7 & 0.232 & 34.6 & 65.4 & 0.145 & 100 \\
\hline Female & 79.9 & 20.1 & & 42.3 & 57.7 & & 100 \\
\hline \multicolumn{8}{|c|}{ Religion } \\
\hline Christionity & 78.6 & 21.4 & & 38.4 & 61.6 & 0.714 & 100 \\
\hline Islam/Other & 68.8 & 31.2 & 0.092 & 35.9 & 64.1 & & 100 \\
\hline \multicolumn{8}{|l|}{ Ethnicity } \\
\hline Yoruba & 74.3 & 25.7 & 0.265 & 32.0 & 68.0 & 0.020 & 100 \\
\hline Igbo/Other & 79.4 & 20.6 & & & 44.2 & 55.8 & 100 \\
\hline \multicolumn{8}{|l|}{ Education } \\
\hline Post-Secondary & 75.8 & 24.2 & 0.659 & 34.1 & 65.9 & 0.114 & 100 \\
\hline Secondary or less & 77.8 & 22.2 & & 42.4 & 57.6 & & 100 \\
\hline \multicolumn{8}{|c|}{ Marital status } \\
\hline Single & 78.3 & 21.7 & 0.236 & 37.2 & 62.8 & 0.622 & 100 \\
\hline Not Single & 72.0 & 28.0 & & 40.2 & 59.8 & & 100 \\
\hline \multicolumn{8}{|c|}{ Type of work } \\
\hline Manager & 82.1 & 17.9 & & 43.2 & 56.8 & 0.217 & 100 \\
\hline Not a manager & 74.7 & 25.3 & 0.147 & 35.9 & 64.1 & & 100 \\
\hline \multicolumn{8}{|c|}{ Smoking status } \\
\hline Current smoker & 73.9 & 26.1 & 0.737 & 43.5 & 56.5 & 0.571 & 100 \\
\hline $\begin{array}{l}\text { Not a current } \\
\text { smoker }\end{array}$ & 77.0 & 23.0 & & 37.5 & 62.5 & & 100 \\
\hline \multicolumn{8}{|c|}{ Type of facility } \\
\hline Restaurant & 76.4 & 23.6 & 0.893 & 40.1 & 59.9 & 0.442 & 100 \\
\hline Bar & 76.5 & 23.5 & 0.905 & 34.7 & 65.3 & 0.150 & 100 \\
\hline Nightclub & 66.7 & 33.3 & 0.170 & 30.0 & 70.0 & 0.348 & 100 \\
\hline \multicolumn{8}{|c|}{ Workplace smoking policy } \\
\hline $\begin{array}{l}\text { Smoking not } \\
\text { allowed anywhere }\end{array}$ & 86.0 & 14.0 & 0.017 & 42.1 & 57.9 & 0.407 & 100 \\
\hline $\begin{array}{l}\text { Partial restrictions } \\
\text { exist }\end{array}$ & 72.6 & 27.4 & & 37.8 & 62.2 & & 100 \\
\hline $\begin{array}{l}\text { No smoking } \\
\text { restrictions }\end{array}$ & 71.4 & 28.6 & & 33.0 & 67.0 & & 100 \\
\hline \multicolumn{8}{|c|}{ Workplace sells cigarettes } \\
\hline Yes & 70.3 & 29.7 & 0.029 & 31.3 & 68.8 & 0.048 & 100 \\
\hline No & 80.7 & 19.3 & & 42.0 & 58.0 & & 100 \\
\hline $\begin{array}{l}\text { Mean number of } \\
\text { clients }\end{array}$ & $75.4(9.6)$ & $53.8(5.7)$ & 0.056 & $86.1(213.7)$ & $60.8(58.2)$ & 0.190 & $70.4(139.6)$ \\
\hline
\end{tabular}

*Smoking allowed outdoors or the presence of designated smoking areas.

Chi-square and t-tests were conducted. 
Table 5: A multivariate analysis of the factors associated with respondents support for complete bans on smoking in restaurants, bars and nightclubs among the workers in hospitality venues in Lagos state, Nigeria

\begin{tabular}{|c|c|c|c|c|c|c|}
\hline \multirow[t]{2}{*}{ Variables } & \multicolumn{3}{|c|}{$\begin{array}{l}\text { Supports ban on smoking in } \\
\text { restaurants }\end{array}$} & \multicolumn{3}{|c|}{$\begin{array}{l}\text { Supports ban on smoking in bars and } \\
\text { nightclubs }\end{array}$} \\
\hline & Odds ratio & $95 \% \mathrm{Cl}$ & P-value & Odds ratio & $95 \% \mathrm{Cl}$ & P-value \\
\hline Age & 1.01 & $0.98-1.04$ & 0.58 & 1.00 & $0.98-1.03$ & 0.95 \\
\hline \multicolumn{7}{|c|}{ Gender } \\
\hline Male & 1 & & & 1 & & \\
\hline Female & 1.36 & $0.80-2.39$ & 0.27 & 1.41 & $0.89-2.25$ & 0.15 \\
\hline \multicolumn{7}{|c|}{ Level of education } \\
\hline Secondary or less & 1 & & & 1 & & \\
\hline More than secondary & 0.89 & $0.53-1.51$ & 0.68 & 0.76 & $0.48-1.19$ & 0.24 \\
\hline \multicolumn{7}{|l|}{ Smoking status } \\
\hline Not a current smoker & 1 & & & 1 & & \\
\hline Current smoker & 0.91 & $0.33-2.51$ & 0.86 & 0.63 & $0.26-1.58$ & 0.33 \\
\hline Workplace sells tobacco & 0.71 & $0.41-1.23$ & 0.22 & 0.60 & $0.37-0.96$ & \\
\hline \multicolumn{7}{|c|}{ Workplace smoking policy } \\
\hline No smoking restrictions & 1 & & & & & \\
\hline $\begin{array}{l}\text { *Partial restrictions } \\
\text { exist }\end{array}$ & 2.14 & $1.02-4.48$ & 0.04 & & & \\
\hline $\begin{array}{l}\text { Smoking not allowed } \\
\text { anywhere on the } \\
\text { premises }\end{array}$ & 2.18 & $1.08-4.14$ & 0.03 & & & \\
\hline \multicolumn{7}{|c|}{ Ethnicity } \\
\hline Yoruba & & & & 1 & & \\
\hline Not Yoruba & & & & 1.70 & $1.09-2.68$ & 0.02 \\
\hline
\end{tabular}

* Smoking allowed outdoors or the presence of designated smoking areas.

bans in bars and nightclubs (OR: 1.7 95\% CI:1.09-2.68). We also observed that compared with respondents who worked in venues where there were no smoking restrictions, those who worked in places with partial restrictions had a 2.14 higher odds (95\% CI 1.02-4.48), of supporting smoking bans in restaurants while those who worked in places where smoking was not allowed anywhere on the premises had a 2.18 higher odds (95\% CI 1.08-4.14). (Table 5)

\section{DISCUSSION}

Our study has demonstrated that many of the employees are unaware of the "State regulation of smoking law" and their knowledge of specific aspects of the law was very poor.

These values $(57.6 \%)$ are lower than figures reported among employees in hospitality venues in Lebanon where the majority ( $82.8 \%$ ) of the employees were aware of their national smoke free laws ${ }^{12}$. Even though, like ours, the Lebanon study was also conducted a few months before the law came into effect, the higher values observed might be because only owners/managers were surveyed in Lebanon whereas majority our respondents were waiters/waitresses. It is possible that owners/managers might be more knowledgeable than other categories of employees. The levels of awareness observed in this study were also slightly lower than the figures reported in a similar study among employees in hospitality venues in Osun state, Nigeria where $75 \%$ of the respondents were aware of the state-wide smoking regulatory laws however, similar to findings in Osun state, knowledge of the specific aspects of the law was also poor ${ }^{11}$. Our results highlight the need to specifically educate this category of employees to increase their awareness of the law.

Similar to our findings, the mass media was a major source of information among respondents in Lebanon ${ }^{12}$, where it was recorded that efforts had been made by the State Ministries for health and the syndicate of restaurant owners to educate the employees in Lebanon about the law. Employees in restaurants, bars and nightclubs are key stakeholders in the successful implementation of smoke-free laws, as these establishments have been highlighted as environments in which both employees and clients have high levels of exposure 
to $\mathrm{SHS}^{13-17}$. When governments enact smoke free laws, it is important to develop strategies to educate not only the general population, but the specific groups of employees who will be involved in the effective implementation of these laws. This is in line with the WHO guidelines for the implementation of article 8 of the FCTC, which recommended that the knowledge, attitudes and support for smoke-free legislation among specific groups, like bar employees as a key process indicator for the monitoring and evaluation of smoke-free laws ${ }^{6}$. The results of this study clearly support findings from other countries that smoke-free policies are often widely supported by the public $^{11,18-20}$. Particularly in hospitals and schools and to a lesser extent in hospitality venues like hotels and bars. These findings are similar to a study carried out in China, where the majority of the population supported the prohibition of smoking in schools and public vehicles (85\%), in hospitals (73\%) and in offices (58\%) while only 17\% supported prohibiting smoking in restaurants and $11 \%$ supported in bars ${ }^{21}$. Similar findings were observed in Poland where the respondents also favoured bans in workplaces, on public transportation and public buildings over bans in bars, pubs and cafes ${ }^{22}$. As more countries pass comprehensive smoke-free policies, although initial debates over smoke-free policies may exist, once people understand the rationale for implementing smoke-free policies and experience their benefits, public support and compliance tends to increase over time ${ }^{23}$.

An analysis of smoke-free legislation in African countries showed that an overwhelming majority of countries (91.3\%) had legislative provisions that permit designated smoking rooms which is in violation of Article 8 of the FCTC.7 After more than 10 years of ratifying the WHO FCTC, a national law banning smoking in public places was eventually passed in Nigeria. As with many other countries in Africa, both the Nigerian national and state laws do not meet the WHO FCTC standards for comprehensive protection from tobacco smoke. Our findings are important for policy makers, as countries strive towards the passage of comprehensive smoke-free laws.

Studies in other parts of the world have demonstrated that smoke-free policies do not reduce revenue in hospitality venues over time ${ }^{24-27}$. Many of the respondents in our study erroneously felt that the "State regulation of smoking law" would decrease revenue. Also, more than half of the respondents felt that the law would reduce the satisfaction of their clients. The low support for comprehensive smoke free bans in restaurants, bars and nightclubs could be as a result of the perceived fear of reduced revenue and customer satisfaction among the respondents. There is a need to educate these employees on the positive effects of comprehensive smoke free bans and garner their support for the implementation of such smokefree policies.

We observed that tobacco sales on the premises may be associated with employee support for smoke free legislations. Respondents who worked in venues where tobacco was sold were less likely to support a ban on smoking in bars/ nightclubs. This might be because of the perceived loss of revenue that may result from a reduction in tobacco sales in venues where tobacco is sold. Future research should consider the role of tobacco sales and its effect of revenue particularly in places where tobacco sales may be a major source of revenue in Nigeria.

We also observed that the presence of organisational smoking restrictions may affect employee support for comprehensive smoke free laws. Compared with respondents who worked in venues where there were no smoking restrictions, those employed in places with smoking restrictions had higher likelihood of supporting comprehensive smoke free bans in restaurants. This might indicate that the implementation of these laws may have some effect on employee attitudes. Findings from the International tobacco control four-country survey support the assertion that the implementation of smokefree policies may affect population support for these policies ${ }^{23}$. Our study has some limitations. The cross-sectional nature of the study does not allow for any causal or temporal inferences. Nevertheless, to our knowledge, this is one of the first studies in our setting to use a probability sampling method to assess the awareness and support for smoke free policies among key stakeholders like employees in hospitality venues.

\section{CONCLUSIONS}

Awareness of the "State regulation of smoking law" was low however majority supported comprehensive smoke free bans in many public places. Support for comprehensive bans in bars and nightclubs was low. Many of the employees felt that the law would either negatively affect their revenue. Support for comprehensive smoking bans was associated with the presence of workplace smoking restrictions and a lack of tobacco sales in the respondents' workplace. Monitoring the awareness and support of employees in hospitality venues for comprehensive smoking bans is essential in line with the guidelines for Article 8 of the WHO FCTC.

\section{REFERENCES}

1. U.S. Department of Health and Human Services. The Health Consequences of Involuntary Exposure to Tobacco Smoke: A Report of the Surgeon General. Atlanta, GA: U.S. Department of Health and Human Services, Centers for Disease Control and Prevention, Coordinating Center for Health Promotion, National 
Center for Chronic Disease Prevention and Health Promotion, Office on Smoking and Health, 2006:3-11

2. World Health Organization. Global health observatory data: Second hand smoke. Available at http://www.who.int/gho/phe/ secondhand_smoke/en/ Accessed March 2016

3. United States Center for Disease Control and Prevention. Second hand smoke facts. Available at http://www.cdc.gov/tobacco/data statistics/fact_sheets/secondhand_smoke/general_facts/ Accessed March 2016

4. Federal Ministry of Health. Global Adult tobacco Survey 2012 Country report. Available at: http://www.nigerianstat.gov.ng/ pages/download/157 (accessed June 2014)

5. World Health Organization. WHO report on the global tobacco epidemic, 2009: implementing smoke-free environments.

6. World Health Organization. Framework Convention for Tobacco Control. Guidelines for implementation of article 8. Available at http://www.who.int/fctc/cop/art\%208\%20guidelines_english. pdf?ua $=1$

7. Tumwine J. Implementation of the framework convention on tobacco control in Africa: current status of legislation. International journal of environmental research and public health. 2011 Nov 17;8(11):4312-31.

8. World Health Organisation Framework Convention on Tobacco Control. Parties to the WHO framework on tobacco control. 2009 Available at: http://www.who.int/fctc/signatories_parties/en/index. html. Accessed January 2012

9. Hybrid quarterly. The LAGOS STATE REGULATION OF SMOKING LAW: implications for workplace. Available at http:// www.hybridsolicitors.com/solicitor/newsletters/THE_LAGOS_ STATE_REGULATION_OF_SMOKING_LAW.pdf. Accessed March 2016.

10. Lagos State 7th Assembly, House of Assembly, Lagos state, 2014. A law to provide for the regulation of smoking in public places and for connected purposes. Lagos state printing corporation, Ikeja, Lagos

11. Onigbogi OO, Odukoya O, Onigbogi M, Sekoni O. Knowledge and attitude toward smoke-free legislation and second-hand smoking exposure among workers in indoor bars, beer parlors and discotheques in Osun State of Nigeria. International journal of health policy and management. 2015 Apr;4(4):229.

12. Alaaeddine G, Kuhaimi Ta, Al Assad R, Dany M, Diab R, Hanna E et al. Assessing knowledge and attitudes of owners or managers of hospitality venues regarding a policy banning indoor smoking. Public health 127 (2013) 461-466.

13. Navas-Acien A, Peruga A, Breysse P, et al. Secondhand tobacco smoke in public places in Latin America, 20022003. JAMA. 2004:291(22):2741-2745.

14. Nebot M, Lopez MJ, Gorini G, et al. Environmental tobacco smoke exposure in public places of European cities. Tob Control. 2005;14(1):60-63.

15. Siegel M, Skeer M. Exposure to secondhand smoke and excess lung cancer mortality risk among workers in the «5 B's»: bars, bowling alleys, billiard halls, betting establishments, and bingo parlours. Tob Control. 2003;12(3):333-338.

16. World Health Organization. Geneva, Switzerland: 2009. WHO Report on the global tobacco epidemic, 2009: Implementing smokefree environments.

17. Hyland A, Higbee C, Borland R, Travers M, Hastings G, Fong G, et al. Attitudes and beliefs about secondhand smoke and smoke-free policies in four countries: Findings from the International Tobacco Control Four Country Survey. Nicotine Tob Res. 2009;11(6):642649. doi: 10.1093/ntr/ntp063.
18. Owusu-Dabo E, Lewis S, McNeill A, Gilmore A, Britton J. Support for smoke-free policy, and awareness of tobacco health effects and use of smoking cessation therapy in a developing country. BMC Public Health. 2011 Jul 18;11(1):1.

19. Sureda X, Fernandez E, Martinez-Sanchez JM, Fu M, Lopez MJ, Martinez C, Salte E. Secondhand smoke in outdoor settings: smokers' consumption, non-smokers' perceptions, and attitudes towards smoke-free legislation in Spain. BMJ open. 2015 Apr 1;5(4):e007554.

20. Goel S, Singh RJ, Sharma D, Singh A. Public opinion about smoking and smoke free legislation in a district of North India. Indian journal of cancer. 2014 Jul 1;51(3):330.

21. Fong GT, Sansone G, Yan M, Craig L, Quah AC, Jiang Y. Evaluation of smoke-free policies in seven cities in China, 2007-2012. Tobacco Control. 2015 Nov 1;24(Suppl 4):iv14-20.

22. Kaleta D, Polaka K, Dziankowska-Zaborszczyk E, Kowalska A, Drygas W, Fronczak A. [Teachers attitudes towards smoke-free regulations]. Przeglad lekarski. 2011 Dec;69(10):983-6.

23. Hyland A, Higbee C, Borland R, Travers M, Hastings G, Fong GT, Cummings KM. Attitudes and beliefs about secondhand smoke and smoke-free policies in four countries: findings from the International Tobacco Control Four Country Survey. Nicotine \& Tobacco Research. 2009 Jun 1;11(6):642-9.

24. Lal A, Siahpush M. The effect of smoke-free policies on revenue in bars in Tasmania, Australia. Tobacco control. 2009 Oct 1;18(5):4058.

25. Buettner Schmidt K, Lobo ML, Travers MJ, Boursaw B. Tobacco smoke exposure and impact of smoking legislation on rural and nonrural hospitality venues in North Dakota. Research in nursing \& health. 2015 Aug 1;38(4):268-77.

26. Caballero Hidalgo A, Pinilla Dominguez J. Impact of new Spanish smoke-free legislation on the business activity of bars, cafes and restaurants. Gaceta Sanitaria. 2014 Dec;28(6):456-60.

27. Cornelsen L, McGowan Y, Currie Murphy LM, Normand C. Systematic review and meta analysis of the economic impact of smoking bans in restaurants and bars. Addiction. 2014 May 1;109(5):720-7. 